\title{
No caminho para o urbanismo. Saturnino de Brito e Édouard Imbeaux, trajetórias profissionais entre Brasil e França
}

\begin{abstract}
Angelo Bertoni ${ }^{1}$
RESUMO: O objetivo deste trabalho é estabelecer um diálogo entre duas trajetórias profissionais, a de Saturnino de Brito (1 864-1929) e a de Édouard Imbeaux (1861-1943), que privilegiaram a cidade como objeto de ação e de reflexão, as quais são construídas a partir de um conhecimento inovador sobre as questões de higiene e saneamento. A especificidade desses percursos é a associação da prática com a reflexão teórica e sua difusão: estes dois profissionais contribuíram, assim, cada um em seu país, para a construção da disciplina urbanística, especialmente em sua abordagem técnica. $\bigcirc$ cenário internacional constitui uma dimensão importante de sua ação, que tornou possível a circulação/confronto de saberes técnicos entre Europa e Brasil e contribuiu com a pesquisa de uma resposta concreta e adaptada aos problemas da cidade. A interação do cenário local, nacional e internacional permite trazer um outro olhar sobre as trajetórias profissionais de Saturnino de Brito e Édouard Imbeaux.

PALAVRAS-CHAVE: Saturnino de Brito. Édouard Imbeaux. Engenharia sanitária. Urbanismo. Trajetórias profissionais.

ABSTRACT: The aim of this work is to establish a dialogue between the professional trajectories of two engineers: Saturnino de Brito (1864-1929) and Édouard Imbeaux (1861-1943). They both focussed on the city as object of action and reflection based on an innovative knowledge of hygiene and sanitation issues. The specificity of these trajectories is the association of practice, theoretical reflection and dissemination: these two professionals respectively contributed, in their countries, to the construction of Town planning as a discipline, in particular in relation to its technical approach. The international scene is an important dimension of their activity as it made possible the circulation / comparison of technical knowledge between Europe and Brazil and it contributed to find a specific and appropriate response to the problems of the city. The interaction of local, national and international scene allows another perspective of the professional trajectories of Saturnino de Brito and Edouard Imbeaux.

KEY-WORDS: Saturnino de Brito. Édouard Imbeaux. Sanitary Engeneering. Town Planning. Professional Trajectories.
\end{abstract}

Professor Doutor Angelo Bertoni: Aix Marseille Université, CNRS, UMR TELEMME. E-mail: <angelo. bertoni@ univ-amu.fr>. 
2. Guido Zucconi (1989).

3. Gilles Montigny (1992).

4. Muitos autores interessaram-se pelas trocas entre profissionais, elites políticas e reformadores: Viviane Claude (1987); Dorothy Porter (1994); Sabine Barles (1999); Martin Melosi (2000); Patrice Bourdelais (2001); Roy Mac Leod (2003).

5. Ver Charles Barde (1891) e Jules Rochard (1891).
Reformar a cidade

Francisco Rodrigues Saturnino de Brito (1864-1929) e Édouard Imbeaux (1861-1943) desenvolveram suas respectivas atividades profissionais durante um período crucial para a consolidação do urbanismo, não só em França e Brasil, mas também na Europa e nos Estados Unidos. A virada do século XX caracterizou-se, em particular na Europa, pela multiplicidade de saberes e disciplinas que buscavam a hegemonia nas questões urbanas: os higienistas, médicos e engenheiros estavam entre os primeiros a reivindicá-la, mas a concorrência dos técnicos municipais e dos arquitetos não demorou muito para se manifestar. Guido Zucconi revelou a batalha de competências que acompanhou a construção do urbanismo na ltália², e, logo depois, Gilles Mortigny fez o mesmo para a França ${ }^{3}$.

A contribuição dos técnicos para a construção da cidade, enquanto objeto de conhecimento, de reforma e de ação, levantou a questão da mudança de escala da intervenção de cada profissão. Na maioria dos casos, a reflexão passou do prédio ao bairro, para chegar à cidade como um todo: os discursos dos higienistas ou dos arquitetos do período mostram bem essa evolução. Várias condições levaram a essa mudança. Por um lado, as pesquisas urbanas mostraram que a dimensão dos problemas a enfrentar excedia a escala de ação vigente até então; por outro, os progressos técnicos e científicos confirmavam a necessidade de uma ação conjunta no meio urbano para alcançar o objetivo de uma "cidade salubre" 4 . Nesse contexto, a aliança entre profissionais e reformadores sociais ou entre técnicos e elites políticas foi determinante para a emergência e consolidação de novos objetos para a prática profissional. Trajetórias de Saturnino e Imbeaux ilustram bem este assunto, no seu diálogo com as autoridades locais e as elites reformistas.

Na maioria dos países europeus, a cidade passou a ser um objeto de estudo para os meios reformadores, nos últimos vinte e cinco anos do século XIX. A questão da salubridade das moradias ${ }^{5}$, as investigações sociais cada vez mais precisas, as primeiras iniciativas para criar leis de habitações operárias e casas econômicas estavam no cerne dos debates sobre a questão social. Muitos profissionais interessaram-se pela cidade e integraram os círculos reformadores: nessas instâncias, engenheiros, higienistas, médicos e arquitetos conviviam com os vereadores e 0 empresariado industrial, não só nas capitais, mas também nas realidades locais. Esses contextos permitem observar relações que Édouard Imbeaux e Saturnino de Brito estabelecem com outros atores envolvidos no campo da higiene urbana e urbanismo em Nancy, Luxemburgo, Santos ou Recife. $O$ plano torna-se a ferramenta para imaginar a cidade e controlar seu crescimento na atuação dos princípios higienistas.

Saturnino de Brito e Édouard Imbeaux: o engenheiro e a cidade salubre

Os percursos profissionais de Francisco Rodrigues Saturnino de Brito e de Édouard Imbeaux confirmam a centralidade das questões de salubridade e o papel das redes técnicas no início do urbanismo, como conhecimento teórico e know-how. 
A formação do engenheiro, caracterizada pela confiança positivista na ciência, fornece as ferramentas para "curar" a cidade. A passagem pela École Polytechnique permite-lhe combinar o conhecimento técnico e científico e ultrapassar a figura do engenheiro artista resultante do lluminismo ${ }^{\circ}$. Aspectos técnicos e sanitários de sua primeira abordagem foram mais tarde postos em ressonância com outros temas ou disciplinas, como a estética, para Saturnino, ou medicina, para Imbeaux.

Saturnino de Brito ingressou na Escola Politécnica do Rio de Janeiro em 1881. Essa escola era o fruto de um longo processo no qual, progressivamente, a engenharia civil vinha separando-se da engenharia militar, como acontecia na Europa, na mesma época. Fundada em 1874, foi organizada em dois cursos, um geral e outro especializado (Cursos Especiais de Ciências Físicas e Naturais, Curso de Ciências Físicas e Matemáticas, Curso de Engenheiros Geógrafos, Curso de Engenheiros Civis, Curso de Engenheiros de Minas e Curso de Artes e Manufaturas)7. Saturnino de Brito optou pelas Artes e Manufaturas no terceiro ano, e obteve o diploma de engenheiro civil com 22 anos, em 1886. No início da carreira Saturnino é contratado nas obras de construção e expansão da malha ferroviária de vários estados brasileiros ${ }^{8}$. A partir dos anos 1892-1893 realiza seus primeiros trabalhos de saneamento e desenvolve particularmente a ferramenta topográfica, muito importante em suas obras sucessivas. De forma progressiva, o tema da expansão urbana surge e acompanha o de saneamento nos trabalhos confiados à Saturnino. Projetos para Vitória, ES, Campos dos Goytacazes, RJ e Santos, SP, revelaram-se cruciais no percurso do engenheiro sanitário, neles, pôde medir a validade dos princípios higienistas que defendia e precisá-los para construir um saber urbano de matriz sanitária.

$\bigcirc$ percurso de Édouard Imbeaux é também profundamente influenciado por seus estudos e experiências em início de carreira. Depois de passar pela École polytechnique (1881-1883) e pela École de Ponts et Chaussées (1883-1886), Imbeaux obteve o diploma de engenheiro de Ponts et Chaussées, em 1886, e começou sua carreira em Apt, Vaucluse - sua primeira missão, onde permaneceu cinco anos. Juntouse, então, aos serviços municipais de Nancy, onde dirigiu até 1912 o Departamento de esgotos, estradas, águas e iluminação. $\bigcirc$ papel de Nancy no contexto francês de reforma social é muito importante e Imbeaux estava em um lugar propício para a reflexão sobre a cidade e sua modernização. A Société industrielle de l'Est, a que pertencia, estava interessada na questão da habitação popular e expansão urbana, permitindo a conexão entre os profissionais, industriais e vereadores. Em Nancy é organizada a primeira exposição francesa d'urbanismo em 1913. A reputação nacional e internacional de Imbeaux constrói-se a partir desse contexto local efervescente.

Engenheiro, médico, arquitecto: a batalha de competências

A relação do engenheiro com outras profissões do urbano dá origem a situações de colaboração ou conflito de acordo com as situações nacionais. Os contextos franceses e brasileiros, os quais nos interessam aqui, apresentavam-se bastante diferentes. No Brasil, uma clivagem entre as duas principais profissões,
6. Ver Antoine Picon (1988).

7. Para a história dessa instituição, ver Pedro Carlos da Silva Telles (1984).

8. Foi contratado nas obras de construção e expansão da malha ferroviária de Leopoldina, MG, Tamandaré, PE e Baturité, CE. 
9. Ver Maria Cristina Wolff de Carvalho (2000).

10. Ver Maria Cristina da Silva Leme (1999). engenheiro e arquiteto, havia surgido progressivamente a partir dos anos 1920, 0 período de formação de Saturnino, e os primórdios de sua carreira foram marcados por um clima de colaboração no intuito de assentar a jovem república em sua estruturação urbana e territorial. A atividade dos arquitetos orientava-se mais para a construção de prédios públicos e a criação de lugares simbólicos nas cidades, o que vinha reforçar a imagem burguesa e urbana. A obra do engenheiro-arquiteto Ramos de Azevedo ilustra bem esse fato9. Os engenheiros, em particular os que privilegiavam uma abordagem de matriz sanitária, como Saturnino de Brito e Victor da Silva Freire, enfocavam mais o saneamento e a expansão das cidades, como mostraram estudos recentes sobre a questão ${ }^{10}$. No contexto francês, os engenheiros envolvem-se rapidamente na engenharia urbana e no saneamento, desenvolvendo por meio da engenharia sanitária saberes e know-how técnicos que orientam fortemente sua ação sobre a cidade. $\bigcirc$ interesse de arquitetos pela cidade emerge tarde e refere-se apenas a uma pequena parte da profissão. A batalha de competências torna-se mais importante nos anos 1910, em função da emergência do debate sobre o urbanismo, considerado como uma ciência para os engenheiros, e uma arte, para os arquitetos-urbanistas. A competição com os médicos também tem proporções diferentes nos dois contextos de estudo. A sua presença nos debates sobre saneamento urbano na França é muito importante, hegemônica até o final do século XIX, quando os engenheiros criaram as suas próprias instituições dentro do movimento de saúde pública. No Brasil, em compensação, os médicos tinham uma participação discreta nos debates sobre a transformação das cidades, apesar de estarem presentes nas administrações e nas comissões urbanas locais.

Formação e afirmação de dois profissionais do urbano

A partir de 1900, Saturnino de Brito e Édouard Imbeaux são cada vez mais solicitados a participar ou realizar projetos e estudos: eles desenvolvem uma expertise que prestam aos diferentes contextos profissionais e políticos. Este é o caso de projetos importantes de saneamento e expansão de Campos dos Goytacazes e Santos propostos a Saturnino entre 1901 e 1905 e das missões d'expertise sobre abastecimento de água e saneamento urbano propostas a Imbeaux pelo Grande Ducado do Luxemburgo. Essas experiências também são importantes para as oportunidades que representam na construção de redes profissionais.

Do saneameto até o urbanismo: os projetos de Campos e Santos de Saturnino de Brito

A experiência de Vitória (1895-1896) permitiu a Saturnino colocar ferramentas do higienismo a serviço da extensão urbana - é a partir dessa missão que saneamento e extensão serão intrinsecamente ligados em sua obra. $\bigcirc$ traçado urbano do Novo Arrabalde baseava-se num estudo pormenorizado das perspectivas e da vista para os monumentos históricos da cidade antiga ou dos relevos, também 
se aproveitava das características naturais do local, uma vez que se adaptava às saliências rochosas, ao litoral e às margens do rio. Com esse procedimento, Saturnino já mostrava os primeiros elementos da síntese entre técnica e estética das obras mais aperfeiçoadas (Figura 1).

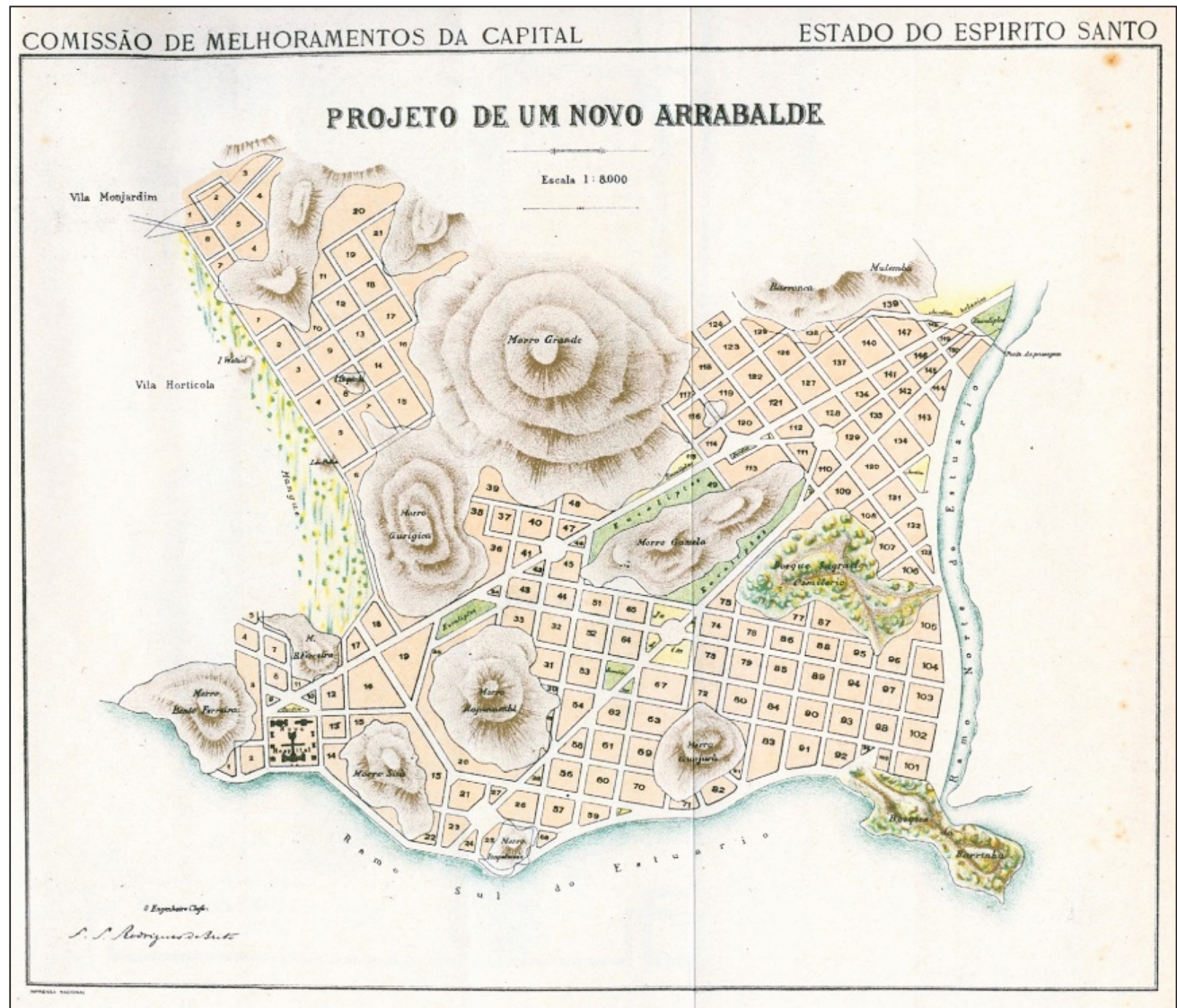

Figura 1 - Francisco Rodrigues Saturnino de Brito. Projeto de um novo arrabalde. Saneamento de Vitória, ES. Fonte: Francisco R. Saturnino de Brito (1943, v. V, est. II, p. 58).

A municipalidade de Campos dos Goytacazes, onde Saturnino nascera, o encarregou, em 1901, do saneamento da cidade, mais particularmente do escoamento de águas pluviais, do conserto da rede de esgotos e da construção de uma rede de abastecimento de água potável. Saturnino acompanha o projeto de um relatório técnico detalhado, o qual abrangia todos os aspectos da questão urbana. Define os princípios e métodos que devem presidir o saneamento das cidades e a sua ampliação. Nele, aborda os diferentes elementos que compõem uma cidade: habitações, prédios públicos, viação pública, parques e jardins, redes técnicas. $\bigcirc$ objetivo mantinha-se no saneamento urbano, mas o apoio material e moral da população tornava-se indispensável para alcançá-lo. Encontramos esta tensão social e cívica nos primeiros manuais europeus de urbanismo, e provém dessa abordagem higienista a designação "males da cidade". 
traçado da rede viária prevista por Saturnino baseava-se nos princípios da higiene urbana, que influíam na definição da largura das ruas e no tipo de revestimento, no número de plantas e do novo perfil dos cais (Figura 2). A orientação das vias também dependia desses princípios e levava em conta os ventos dominantes. Os diferentes elementos que compõem a esfera pública são apresentados por Saturnino como um conjunto orgânico da cidade: precisam ser levados em conta para que os melhoramentos trazidos pelo saneamento urbano, resultado de uma abordagem coerente entre as partes e o todo, sejam bemsucedidos. Ao abordar o traçado viário, Saturnino exprimiu uma posição original e coerente com a sua abordagem sanitária da cidade: estabeleceu uma relação estreita entre topografia e traçado das ruas para obter o melhor escoamento de águas e propôs adaptar o traçado das ruas ao relevo do terreno. Era, portanto, o contexto e o respeito dos princípios higiênicos que determinavam o desenho das vias e não mais a aplicação de sistemas determinados a priori. A construção de um canal para drenar as águas pluviais completava o sistema de saneamento: viraria uma constante nos projetos seguintes e daria resultados surpreendentes.

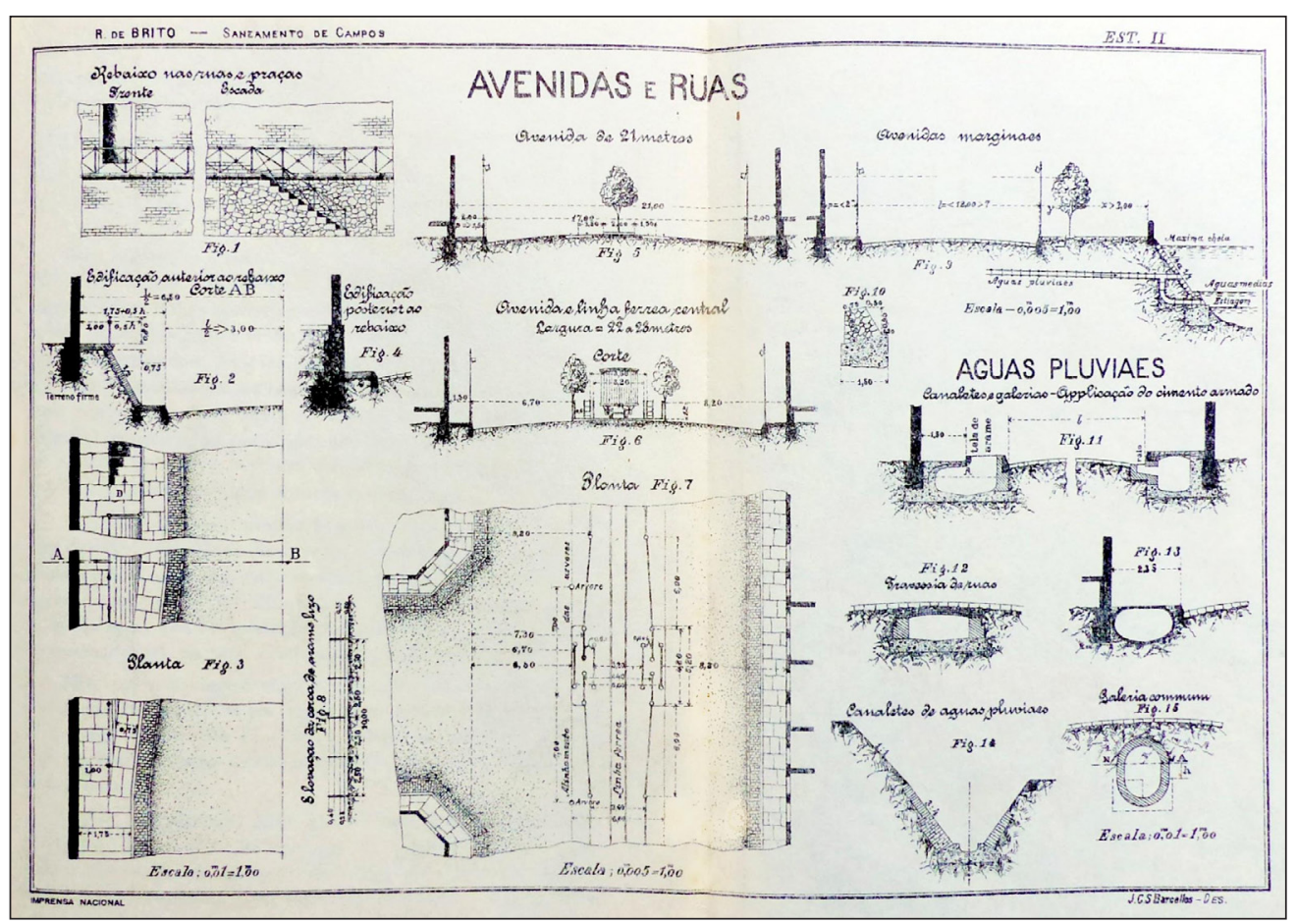

Figura 2 - Francisco Rodrigues Saturnino de Brito. Avenidas e ruas. Saneamento de Campos, RJ. Fonte: Francisco R. Saturnino de Brito (1943, v. VI, est. II, p. 174).

Alguns anos mais tarde, em 1905, Saturnino de Brito foi nomeado diretor da "Comissão de Saneamento de Santos" e o programa das obras, previamente limitado à construção da rede de esgotos, foi ampliado para uma reflexão geral sobre a cidade, até o desenvolvimento do porto e da ferrovia. A cidade transformou- 
se no principal porto brasileiro de exportação de café, e a população quadriplicou de 1886 a 1900, quando foi estimada em aproximadamente 50.000 habitantes. Entre 1905 e 1910, Saturnino projetou e realizou um plano de saneamento e de expansão de Santos, para o qual adotou, apenas parcialmente, uma trama ortogonal, então comum nas cidades americanas. Com essa escolha, conseguiu, por um lado, respeitar as poucas construções existentes e os seus terrenos e, por outro, introduzir princípios estéticos de composição urbana na organização espacial da cidade. $\bigcirc$ estudo e a construção das redes técnicas urbanas, antes de implementar o plano de expansão, permitiram a Saturnino inventar e aperfeiçoar aparelhos técnicos e a utilização de um novo material, o concreto armado. Sua capacidade de inovação colocou-se a serviço das soluções técnicas mais adequadas para o contexto operacional e economia do projeto.

Os canais de drenagem constituíam o elemento-chave do planejamento para Santos (Figura 3). Cruzavam de lado a lado a península onde está a cidade e desempenhavam o papel de novos espaços públicos urbanos - eram "avenidas sanitárias", com largura de 30 a 35 metros, que permitiam uma melhor circulação do ar na cidade. Estavam conectados à avenida-parque que constituía a espinha dorsal do novo plano de Santos, aspecto reforçado pelos espaços reservados às plantas e ao passeio criados ao longo do seu percurso. Para interromper as perspectivas, às vezes extensas demais, previa pequenas praças ou jardins, assim

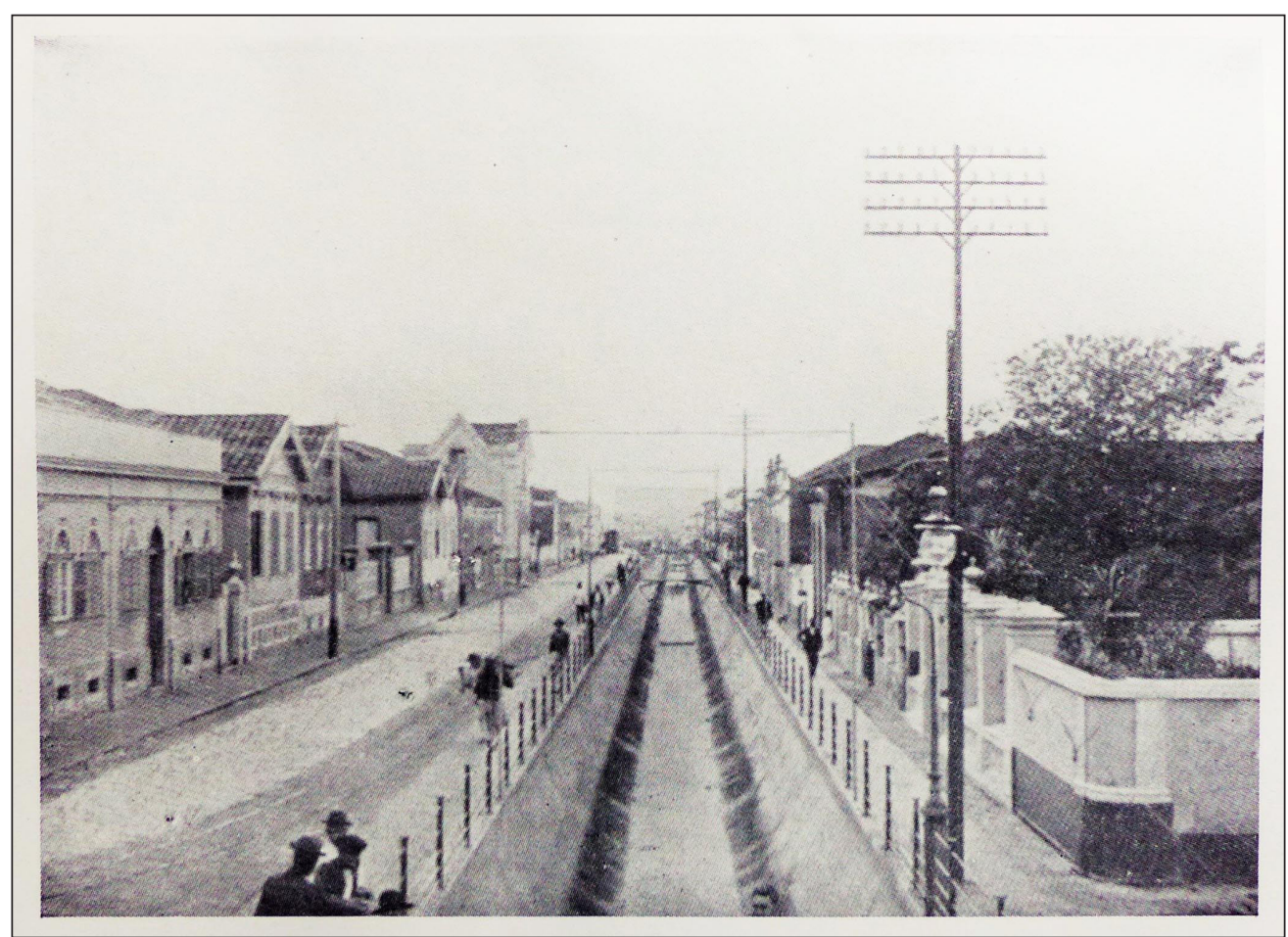

Figura 3 - Francisco Rodrigues Saturnino de Brito. Saneamento de Santos: Canal - Trecho na rua Rangel Pesata (concreto armado). Fonte: Francisco R. Saturnino de Brito (1943, v. VII, est. XII, p. 98).
11. Ver Charles Beveridge e Paul E. Rocheleau (1998) e Bénédicte Leclerc (1994). 
como havia proposto em Vitória. Os prédios públicos ou equipamentos técnicos vinculados com o saneamento eram implantados nas encruzilhadas das vias principais e contribuíam para ritmar o espaço. $O$ plano de saneamento e de expansão de Santos constitui uma ilustração exemplar do "traçado sanitário" definido por Saturnino de Brito, e mostra claramente as suas capacidades para introduzir no Brasil certos elementos oriundos de experiências urbanas europeias e norte-americanas, embora adaptados ao contexto local. A avenida-parque é interpretada de maneira notável de acordo com princípios definidos pelo arquitetopaisagista Frederick Law Olmsted e difundidos no mundo francófono por Jean Claude Nicolas Forestier desde o começo do século XX'1!

A expertise transnacional sobre a água: as missões de Imbeaux, o GrãoDucado do Luxemburgo

O cargo de diretor dos serviços técnicos da cidade de Nancy (França) é crucial para entender a carreira de Édouard Imbeaux. Ele ocupa durante mais de duas décadas esta posição que the permite entrar em contato com diversas realidades, inclusive para além das fronteiras. Com a sua participação em redes de reformadores de Nancy, ele coloca em prática a reconciliação entre profissões em instituições nacionais, principalmente em torno de técnicas urbanas. Sua dupla formação, engenheiro e médico, é rara no mundo da higiene urbana, não só na França. Sua especialidade é o abastecimento de água potável, da qual estudou o papel higiênico em sua tese de medicina, dedicando a este tema artigos e livros e dirigindo muitos projetos.

Poucos anos depois de sua chegada em Nancy, Imbeaux contribui para o nascimento da primeira revista francófona de engenharia sanitária. Este episódio, detallhado na próxima seção, é um ponto de viragem na sua trajetória profissional. Os anos no início do século XX são importantes para a sua afirmação no cenário internacional, mas também para o seu reconhecimento pelos meios locais e nacionais, como evidenciado por sua nomeação para presidente da Academia de Stanislas em 1907 e membro correspondente da Academia de Ciências na seção de economia rural em 1912.

Édouard Imbeaux desempenha o papel de protagonista no campo da engenharia sanitária na escala transnacional. É solicitado pelo município de Luxemburgo várias vezes entre o final do século e início dos anos 1900. Após ter estudado a captação de fontes para melhorar o abastecimento de água potável da cidade, solicitou-se dele o estudo das obras necessárias para o saneamento de Luxemburgo e seus subúrbios. Nesta missão, ele é acompanhado por Karl Höpfner, engenheiro da cidade de Kassel. Nesse território, composto de vários platôs separados por vales estreitos, a expansão urbana foi em grande parte absorvida pelas comunidades em torno da capital e resultou em um desenvolvimento caótico e insalubre, caracterizado por uma superposição de casas e fábricas. Mediante a adopção de princípios de higiene, Imbeaux e 
Höpfner propõem a extensão de redes técnicas urbanas, incluindo abastecimento e eliminação de água: o seu pensamento para além da escala da cidade chega à escala da aglomeração, em uma perspectiva pertinentemente urbanística. O seu trabalho leva em conta os projetos em curso para, na sequência, realizar a construção de novos bairros planejados pelo engenheiro-arquiteto Joseph Stübben para o oeste e o norte da cidade. Este estudo demonstra a complementaridade entre a abordagem sanitária e arquitetônica que Imbeaux defende na definição e construção da cidade salubre.

Contribuições para a engenharia sanitária

Saturnino desempenhou um papel ativo no cenário profissional, nacional e internacional. A força da sua prática fez com que não fosse subordinado aos colegas europeus e norte-americanos. Encampou uma posição compartilhada por outros especialistas brasileiros da sua época na relação que mantinham com as práticas dos seus homólogos estrangeiros: à recusa de importar e tomar de empréstimo soluções executadas em outros lugares, somando-se uma valorização do contexto local e das suas especificidades. Saturnino foi um homem de campo tanto quanto um teórico: sua carreira caracterizou-se pelo diálogo perpétuo entre a prática profissional exercida na transformação de muitas cidades brasileiras e a reflexão teórica alimentada pelas leituras e trocas com colegas brasileiros e estrangeiros. $\bigcirc$ campo da engenharia sanitária permitia-the, ao mesmo tempo, trazer soluções para os problemas de saneamento e desenvolver ferramentas para refletir sobre a expansão urbana. Nesta passagem está a originalidade de Saturnino de Brito em relação a outros engenheiros sanitários da época.

A figura de Édouard Imbeaux ilustra uma situação menos favorável para a implementação dos princípios higienistas fora das operações de saneamento, porque o planejamento não se constitui na França como prática e como mercado após a Primeira Guerra Mundial e a promulgação da Lei Cornudet (1919). Entre o final do século e os anos 1910, Imbeaux desempenha um papel importante na afirmação do engenheiro no debate francês sobre o saneamento urbano e trabalha para uma maior colaboração entre os diferentes profissionais envolvidos no processo de reforma. Convencido de que para dotar de salubridade e higiene as cidades não se mostra suficiente ter como objetivo somente a habitação ou casa salubre, Imbeaux considera necessária uma discussão mais ampla, que inclui redes, espaços abertos e circulação. Defende uma visão global, mais cedo e mais claramente do que Saturnino, mas ao contrário de seu colega brasileiro, suas experiências são limitadas ao campo de redes técnicas urbanas. Os dois homens têm em comum uma experiência reconhecida em abastecimento de águas e drenagem, mas a respectiva prática profissional não os levou a experimentar da mesma forma a implementação dos princípios higienistas. 
12. Saturnino era membro de importantes associações brasileiras e internacionais, entre as quais citaremos: Clube de Engenharia do Rio de Janeiro; Instituto de Engenharia de São Paulo; American Water Works Association; Commission Internationale des Pentes d'Égouts; Association des Hygiénistes et Techniciens Municipaux.

13. Ver Angelo Bertoni (2010) e Carlos Roberto Monteiro de Andrade (1996b).

14. Nouveaux systèmes d'égouts. La Technique sanitaire, n. 5, mai 1907; Les égouts de Rio de Janeiro. $L a$ Technique sanitaire, n. 2, février 1909; Réservoirs de chasse automatiques. La Technique sanitaire, n. 11, novembre 1909; Le pompage en route. $L a$ Technique sanitaire et municipale, n. 12, juillet 1924; Les pentes des branches d'égout. $L a$ Technique sanitaire et municipale, n. 16, novembre 1924.

15. Em 1913, Saturnino de Brito anunciou nas páginas de La technique sanitaire que estava escrevendo um livro sobre o saneamento nas cidades brasileiras.

\section{Fazer a experiência falar: o saber em ação}

Ao longo de sua carreira, Saturnino de Brito produziu inúmeros escritos, compilados em vinte e dois volumes entre 1942 e 1944. Fossem eles relatórios técnicos que acompanhavam os projetos de saneamento ou textos teóricos gerais, todos demarcavam-se no cenário contemporâneo pela riqueza de citações, de notas bibliográficas e de referências científicas. Saturnino foi, provavelmente, um dos técnicos urbanos mais cultos e melhor informados de sua época. Como era membro de associações nacionais e internacionais de profissionais do urbano ${ }^{12}$ conseguiu construir uma rede eficiente de correspondentes e ficar a par das últimas experiências em termos de saneamento e transformação das cidades. Assim, desempenhou um papel de protagonista na cena brasileira: por um lado participou ativamente da construção de um saber técnico urbano baseado na própria prática profissional; por outro, contribuiu para a circulação de ideias e modelos elaborados fora do Brasil, ao integrá-los em seus projetos e realizações ${ }^{13}$.

Dos escritos de Saturnino, alguns textos para conferências ou artigos e livros são particularmente pertinentes aqui - os produzidos com a intenção de fazer circular ideias, especialmente quando Saturnino decide usar a língua francesa. Antes da publicação de seu manual Notes sur le tracé sanitaire des villes [Notas sobre o traçado sanitário das cidades], alguns artigos publicados na revista La Technique sanitaire ${ }^{14}$ permitem a Saturnino comentar os sistemas utilizados nas cidades brasileiras. Esses textos ilustrados com diagramas e desenhos técnicos destinavam-se a uma comunidade de engenheiros sanitaristas e especialistas em higiene urbana. Uma dimensão operacional determinava o ponto de vista de Saturnino que também aproveitava sua experiência direta.

No final da década de 1910, Saturnino redigiu uma nota destinada ao Congresso dos Prefeitos de Pernambuco, que constitui uma síntese dos princípios de saneamento e de melhoramentos das cidades. Esse texto contribui para iluminar os conteúdos da noção de "melhoramentos" que compreende o traçado urbano, o saneamento, os prédios públicos e privados, a iluminação e a viação públicas. Para realizar esses objetivos, o plano geral tornava-se a ferramenta privilegiada. $\bigcirc$ discurso de Saturnino ecoava, aqui, os manuais europeus da época, fundamentados numa visão total da cidade, síntese de saneamento, embelezamento e ampliação. Os textos de Saturnino escritos após 1913 beneficiam-se de sua viagem à Europa, como veremos mais tarde, e dedicam uma grande atenção a alguns relatórios e livros que adquiriu nessa ocasião. O manual de Robert de Souza, L'avenir de nos villes: Nice capitale d'hiver [O futuro das nossas cidades: Nice, capital de inverno] (Figura 4), apresentado em Nancy em 1913, também constituiu, para Saturnino, uma importante fonte iconográfica e uma referência para a atualidade dos concursos de urbanismo.

Notes sur le tracé sanitaire des Villes (Figura 5) marca o culminar do pensamento de Saturnio de Brito - em preparo já há alguns anos ${ }^{15}$, este manual publicado na França em 1916 e com prefácio de Édovard Imbeaux, pretendia atingir a transformação e a expansão das cidades de acordo com os princípios da 
engenharia sanitária. $\bigcirc$ idioma de redação do texto, o francês, exprimia o sentimento de pertencimento de Saturnino à comunidade francófona de especialistas do urbano e a vontade de difundir as próprias teorias além das fronteiras brasileiras $^{16}$. Depois de ter abordado os diferentes tipos de organização espacial e os aspectos legislativos que devem acompanhar a implementação de planos gerais, Saturnino de Brito relaciona a sua prática profissional com as diferentes situações que enfrentou no saneamento e na expansão das cidades. Para ele, foi uma oportunidade de voltar aos projetos de Santos e Recife e reafirmar, mais uma vez, a eficiência da abordagem urbana da engenharia sanitária. A construção de redes técnicas e viárias adaptadas à topografia tornava-se o suporte privilegiado para a expansão urbana, assim, Saturnino de Brito chegou a uma proposta original no panorama das teorias urbanas então discutidas na Europa e nos Estados-Unidos.
16. Essa obra foi ampla e eficientemente estudada por Carlos Roberto Monteiro de Andrade, em particular em relação ao manual de Camillo Sitte, L'art de bâtir les villes, Vienne, 1889. Ver Carlos Roberto Monteiro de Andrade (1992) e (1996a).

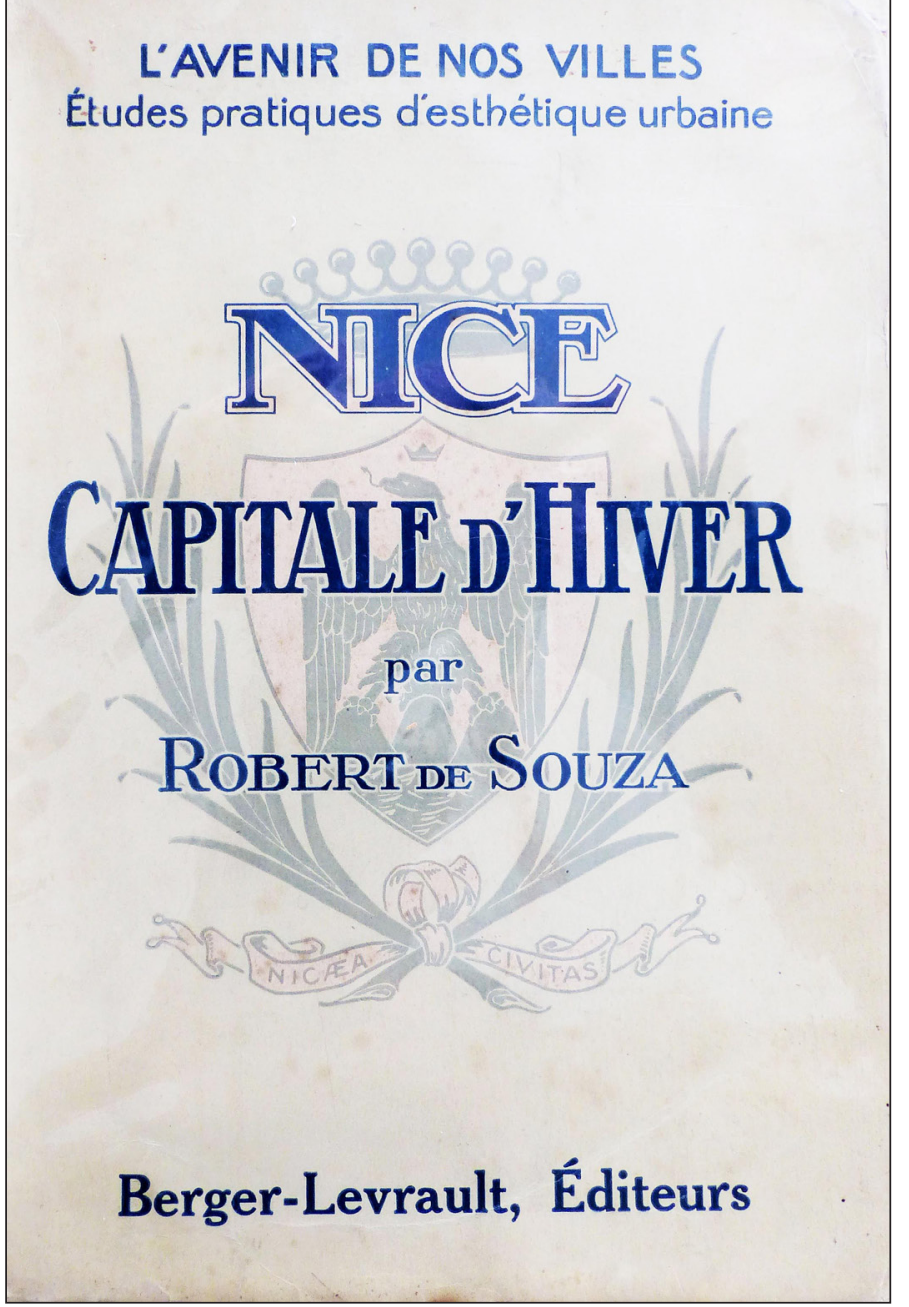

Figura 4 - Capa de L'avenir de nos villes. Nice capitale d'hiver. Fonte: Robert de Souza (1913).

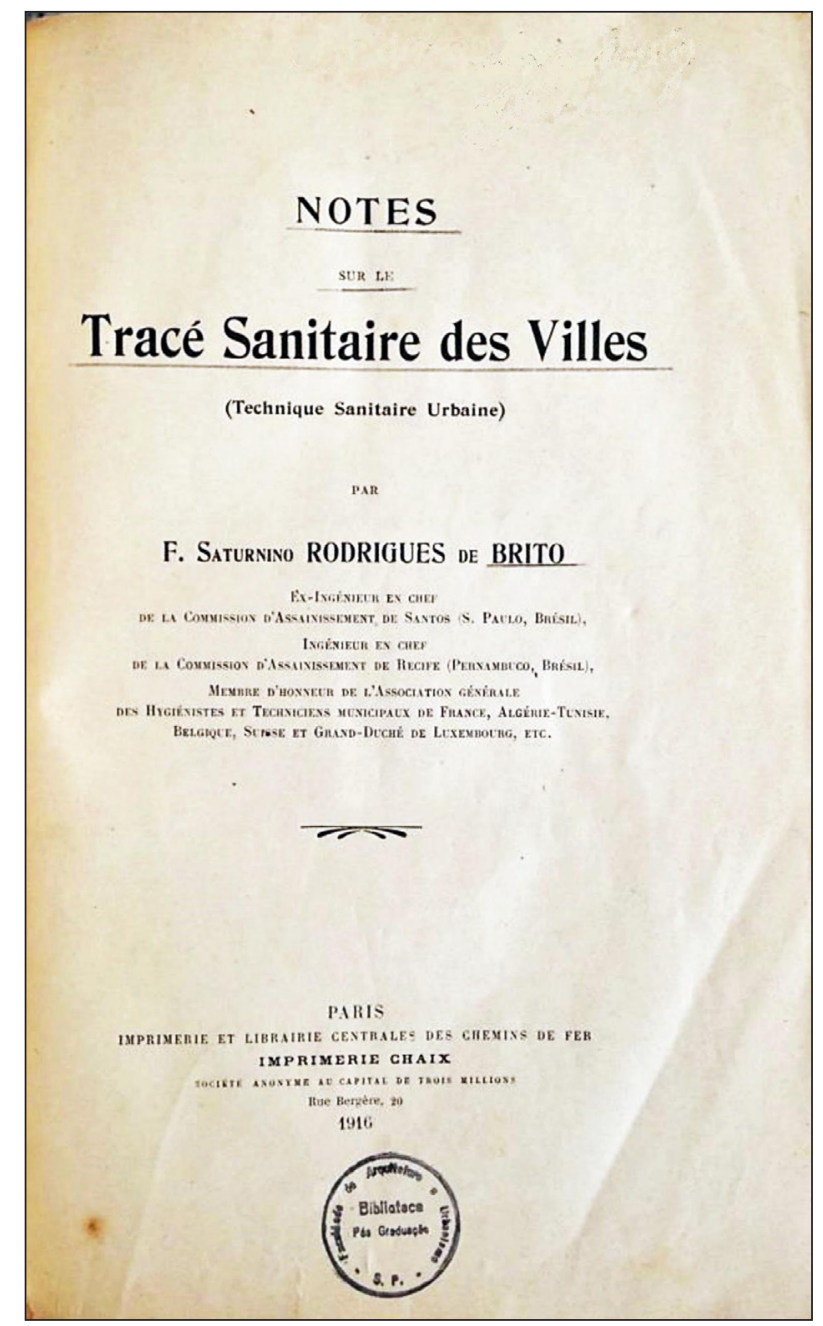

Figura 5 - Capa de Notes sur le tracé sanitaire des villes. Fonte: Francisco R. Saturnino de Brito (1916). 
17. Ver Édouard Imbeaux (1902).

18. Hygiène générale des villes et des agglomérations communales (1910); Égouts et vidanges, ordures ménagères, cimetières (1911)

19. Ver Édouard Imbeaux; Eugène Macé (1910, p. 348352).
A abordagem científica a serviço da cidade: Édouard Imbeaux

Imbeaux acompanha sua carreira como engenheiro-chefe de Ponts et Chaussées de uma importante reflexão sobre o papel que a água desempenha no saneamento urbano, em suas diversas facetas. Sua contribuição para o estabelecimento de uma cultura urbana compartilhada para a comunidade internacional de profissionais passa pela publicação de artigos na imprensa nacional e internacional e de livros ou capítulos de livros no amplo campo da higiene. Com sua dupla formação em engenharia e medicina, Imbeaux pôde estabelecer um diálogo frutífero com outros especialistas de questões urbanas e firmar-se gradualmente como um ator-chave no cenário francês e francófono. Sua longa experiência profissional em Nancy permitiu-the aplicar o conhecimento científico, alimentando assim sua reflexão teórica.

É a partir de sua tese, publicada em 1897, sobre o papel higiênico da água e sua aplicação em Meurthe et Moselle, que o abastecimento de água e o saneamento das cidades tornam-se inseparáveis na produção escrita de Imbeaux. Este será também 0 título de seu primeiro livro ${ }^{17}$ (Figura 6), apresentado na Exposição Universal de Paris em 1900, na qual relatou o problema em vários países: este livro permite-the tomar uma posição clara na cena internacional e de tecer ligações importantes com colegas franceses e europeus. As seguintes publicações esclarecem essa inserção no meio da higiene e engenharia sanitária: Imbeaux estava envolvido na elaboração do importante Tratado de higiene, coordenado por Chantemesse e Mosny e publicado em fascículos a partir do início do século; em relacionar-se com os outros autores nos volumes XII e XV do Tratado ${ }^{18}$, como Albert Calmette, diretor do Instituto Pasteur de Lille, Émile Putzeys, engenheirochefe da cidade de Bruxelas e Eugène Macé, professor de higiene em Nancy. Preocupado com a drenagem e os esgotos, Imbeaux mostra uma profunda compreensão das realidades europeias e norte-americanas e não deixa de dedicar uma longa citação à obra de seu amigo Saturnino em Santos.

Se as condições de vida, moradia e trabalho melhoraram na Europa desde meados do século XIX, Imbeaux aponta a desigualdade na realização de medidas de saneamento pelos diversos municípios e descreve sua visão de "cidade sanitária modelo"19, para criar a partir do zero. Idealmente localizada em um terreno moderadamente inclinado, a organização espacial baseia-se em uma grade voltada para a direção dos ventos dominantes, e propõe ruas tão largas quanto a altura dos edifícios, a fim de facilitar a circulação de ar e luz solar. Alguns blocos são reservados para espaços públicos, praças e jardins; parques e bosques estão na periferia da cidade. Aqui encontramos os elementos essenciais codificados em engenharia sanitária para o saneamento urbano.

Além das semelhanças óbvias, os escritos de Saturnino e Imbeaux já se distinguem neste momento por uma relação diferente para o sítio e a forma urbana. Saturnino, já em 1890, estabelece uma estreita ligação entre o contexto geográfico, o saneamento e a expansão urbana: recomenda tirar o melhor partido dos declives 
naturais para construir um sistema de esgoto eficaz e determinar assim a organização espacial de novos bairros urbanos de acordo com a "topografia sanitária". Imbeaux parece permanecer confinado a uma visão mais técnica ou abstrata da cidade, reduzida ao seu funcionamento e sua eficácia.

A água permanece no centro da sua abordagem ao saneamento, reforçada na cadeira de hidráulica aplicada à École Nationale des Ponts et Chaussées em 1912. A contribuição de Imbeaux para a dimensão sanitária do urbanismo diminui gradualmente após a Primeira Guerra Mundial: a sua atividade na década de 1920 encaminha-se para contribuições que compreendem da biologia à engenharia e à hidrogeologia. Seu último livro, em 1930, contém uma descrição hidrogeológica sistemática da maior parte do território francês, o primeiro trabalho deste tipo.

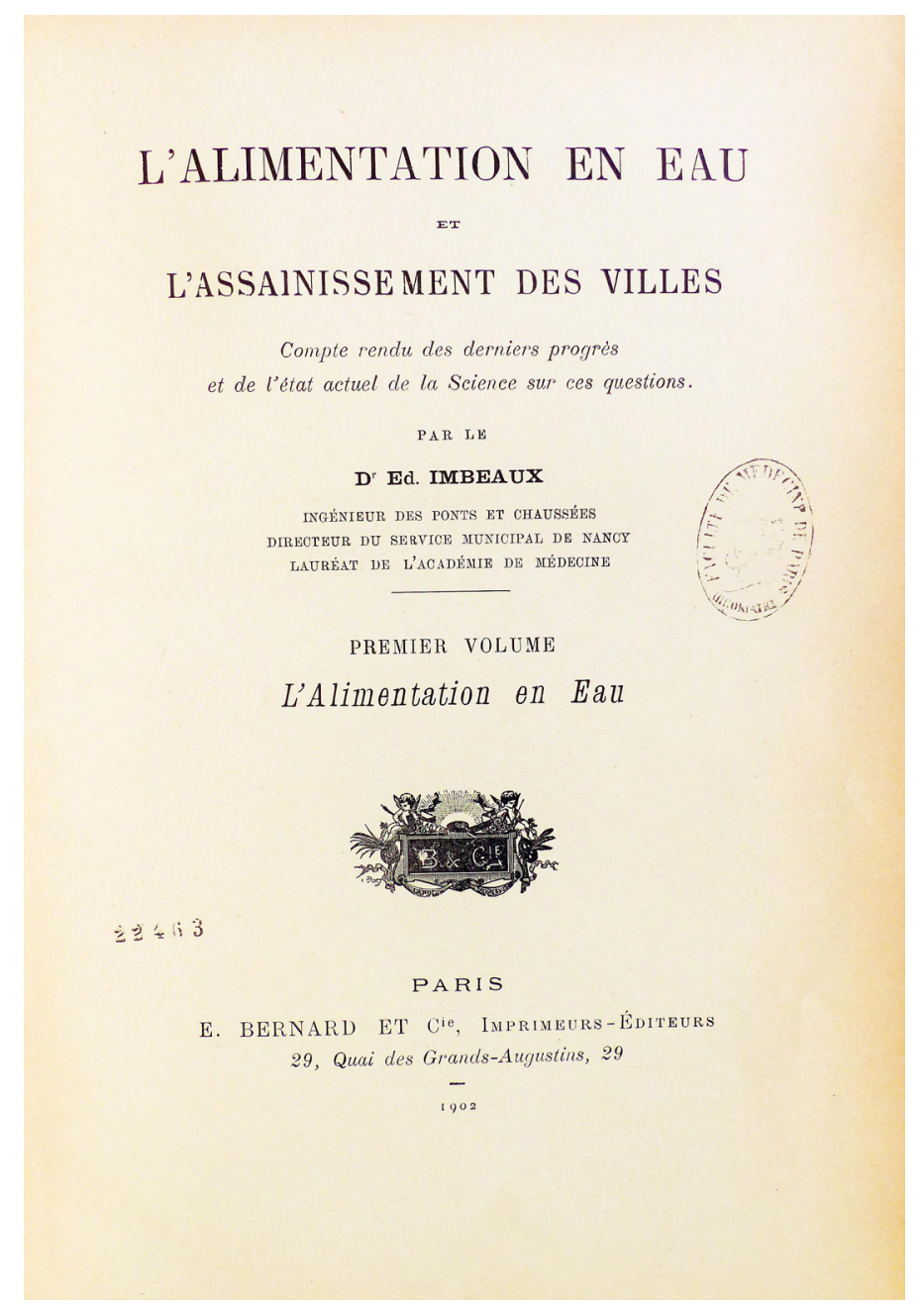

Figura 6 - Capa de L'alimentation en eau et l'assainissement des villes. Compte rendu des derniers progrès et de l'état actuel de la science sur ces questions. Fonte: Édouard Imbeaux (1901). 
20. Ver Jacques Julliard (1987); Jacqueline PluetDespatin; Michel Leymarie e Jean-Yves Mollier (2002).

21. Ver Angelo Bertoni (2006) cénario international, entre circulação dos saberes e afirmação profissional

Édouard Imbeaux e Saturnino de Brito desempenham na cena internacional papéis diferentes. $\bigcirc$ primeiro é particularmente ativo na criação e animação de redes de profissionais, por meio de revistas e associações, como já vimos, mas também por intermédio da organização de eventos e, em menor medida, pela expertise. Saturnino desempenha, em primeiro lugar, o papel do passeur, contribuindo para a circulação no Brasil de conhecimentos técnicos desenvolvidos no mundo, e num segundo momento, após juntar-se às redes internacionais, contribui ativamente para a construção e desenvolvimento dos mesmos conhecimentos, enviando suas contribuições para conferências internacionais e publicando artigos em francês.

$\bigcirc$ empenho de Imbeaux no cénario international permite-lhe aumentar sua reputação no cenário nacional, como revela sua nomeação para um cargo de professor na École des Ponts et Chaussée, mas também na cena local, na qual recebeu vários prêmios nas instituições da cidade de Nancy, como a prestigiosa Academia Stanislas. O reconhecimento obtido por Saturnino na prática profissional e a qualidade das suas intervenções escritas tiram proveito de suas habilidades e conhecimentos: a dimensão internacional é a única capaz de valorizar seus trabalhos em uma real circulação dos saberes entre a Europa e a América Latina.

Revistas e associações: locais de intercâmbio e divulgação

papel das revistas e associações é fundamental para o estudo das trajetórias de Saturnino e Imbeaux, nesse momento considerado pelos historiadores como a idade de ouro de revistas ${ }^{20}$, os periódicos também tornam-se lugares de encontro de trajetórias individuais e contribuem para a criação ou consolidação de pequenos grupos de atores. Vários estudos concentram-se na caracterização de revistas como laboratórios de ideias ou de bancos de ensaio, incluindo a possibilidade que oferecem aos iniciantes para expressar suas ideias, para ter uma plataforma: este é o caso das revistas de engenharia sanitária e, mais tarde, de urbanismo, que não encontram lugar nos periódicos existentes. A revista estabelecese como lugar de circulação e do intercâmbio de pessoas e ideias ${ }^{21}$.

Depois de dar origem a experiências nacionais, incluindo França, Itália e Inglaterra, higiene e saneamento urbano de habitações estão na origem das primeiras iniciativas internacionais que reúnem especialistas, primerio em torno de uma revista, depois de uma associação. A primeira experiência é a revista La Technologie sanitaire [A Tecnologia Sanitária], publicada em Bruxelas desde 1895. Este é o embrião de uma maior iniciativa que mobiliza, alguns anos mais tarde, um grande número de técnicos e profissionais europeus e não europeus, em que a língua francesa é o denominador comum.

La Technologie sanitaire: moniteur des distributions d'eau et d'hygiène appliquée, revista internacional bimensal fundada em Bruxelas em junho 1895, 
destina-se à difusão de conhecimentos técnicos, como indicado pelas motivações do comitê fundador do qual faz parte Édouard Imbeaux:

L'alimentation en eau, qui est le facteur capital de la salubrité des agglomérations humaines et en quelque sorte le point de départ de tous les grands travaux d'assainissement, tient actuellement une place considérable dans les préoccupations des administrations publiques. Dans toutes les villes importantes le service des eaux est un rouage de premier ordre. Si l'on considère les graves intérêts financiers et hygiéniques attachés à une distribution, on reconnaîtra combien il serait utile de résumer périodiquement tous les documents nouveaux relatifs à l'adduction des eaux dont l'étude peut être utile à l'ingénieur ou à l'administrateur. Il n'existe en langue française aucune publication en ce genre. Le nouvel organe s'attachera à combler cette lacune. ${ }^{22}$

Édouard Imbeaux e o belga Victor Van Lint continuam esta experiência em 1905 e lançam uma nova revista e uma associação, com ambições mais internacionais. Para estabelecer relacionamentos contínuos entre técnicos franceses, no dia 22 de novembro de 1905 é fundada em Paris a l'Association générale des ingénieurs, architectes et hygiénistes municipaux de France, Algérie-Tunisie, Belgique, Suisse et Grand-Duché de Luxembourg [Associação Geral de engenheiros, arquitetos e higienistas municipais de França, Argélia, Tunísia, Bélgica, Suiça e do Grão-Ducado do Luxemburgo - AGIAHM]. Este grupo já havia sido pensado em 1898, entre os belgas, franceses e suíços, e deu origem a um primeiro recenseamento comum. A associação, sob a bandeira da língua francesa, agrupa vários profissionais e países e conta com o apoio de muitos ministros dos países francófonos e, na França, da Alliance d'hygiène sociale ${ }^{23}$, conjunto das associações federadas pelo Musée social em torno do tema da higiene e do saneamento das cidades. Saturnino de Brito é um correspondente da associação, que inclui especialistas europeus e americanos de higiene urbana e saneamento das cidades: Luigi Pagliani, William Bryan, Elzear Pelletier, Gustave Richert, Gustavo Villanueva, etc $^{24}$.

A associação tem como objetivo construir relações profissionais entre técnicos francófonos: La Technique sanitaire (Figura 7) empenha-se em contrastar os poderosos meios ingleses e alemães, sem se opor ao desenvolvimento de uma rede de correspondentes não francófonos, e contribui para a construção e circulação de um conhecimento urbano por meio da publicação de artigos, enfocando as principais áreas de atividade da associação: as redes técnicas urbanas, incluindo abastecimento de água esgotos e drenagem, e o saneamento urbano $^{25}$. A participação dos membros é importante, tanto quanto a abertura a outros especialistas francófonos. Imbeaux está entre os mais ativos, com o engenheiro sanitarista parisiense Bernard Bezault - de fora, é importante assinalar a participação do arquiteto Augustin Rey, perito em questões de habitação. Os artigos são ilustrados por fotos, quadros estatísticos, desenhos e gráficos e dão uma contribuição significativa para a construção do conhecimento compartilhado.
22. Cf. La Technologie sanitaire, juin 1895, [O abastecimento de água, que é o fator-chave para a segurança dos assentamentos humanos e de alguma forma o ponto de partida de todas as grandes obras de drenagem, atualmente ocupa um lugar importante na agenda dos governos. Em todas as principais cidades o serviço de água é uma engrenagem na primeira ordem. Se considerarmos os graves interesses financeiros e de higiene ligados a uma distribuição, reconhecemos como seria útil resumir periodicamente todos os novos documentos relativos ao abastecimento de água, de quem o estudo pode ser útil para o engenheiro ou o administrador. Não há publicação em língua francesa neste gênero. $O$ novo jornal vai tentar preencher esta lacuna]. Um importante suplemento de quatro páginas pode indicar os artigos "publicado pela imprensa especializada de todo o mundo" e as notícias de leilões, novas patentes e a criação de empresas. Vontade de participar ativamente da circulação de conhecimentos técnicos urbanos é reforçada pela criação de uma rede de c or r e s o n d e n t e s estrangeiros em Inglaterra, Alemanha, Itália, Espanha, Egito, Romênia e Estados Unidos. A abertura internacional da revista e seus editores é um elemento essencial do seu sucesso e da sua ampla difusão.

23. Ver Lion Murard e Patrick Zylberman (1998).

24. Ver Viviane Claude (1999).

25. Uma seção importante é recuperada de $L a$ Technologie sanitaire, "Índice bibliográfica" é uma fonte importante para os domínios da ação de AGIAHM. Os índices permitem apreciar a riqueza das contribuições que vão 
de saneamento, desde a captação e abastecimento de água, do funcionamento dos serviços, a redes viárias e arte dos jardins.

26. Ver Viviane Claude (1999, p. 278-279).

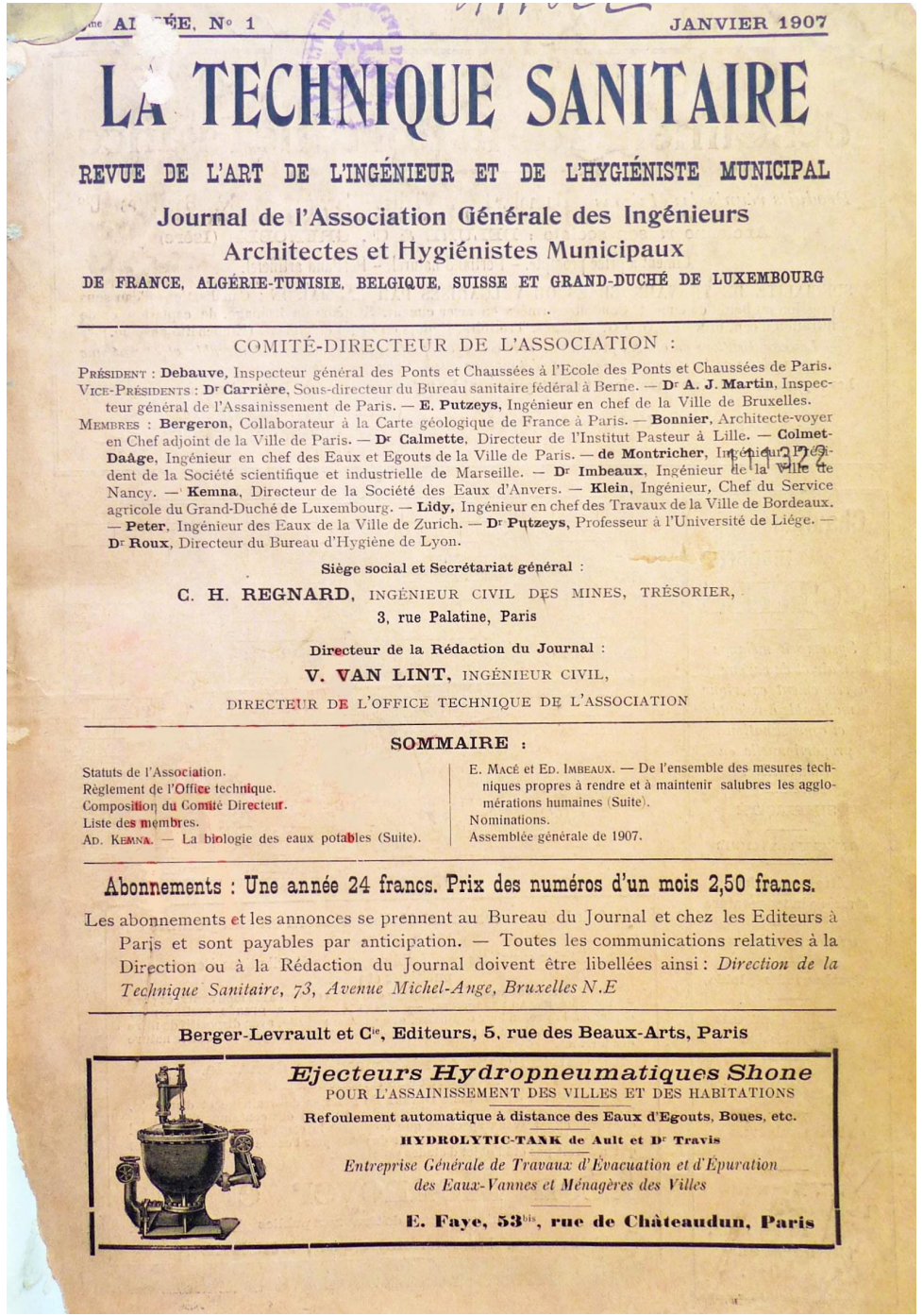

Figura 7 - Capa de La Technique sanitaire. Fonte: Association Générale Des Ingénieurs, Architectes Et Hygiénistes Municipaux. (n. 1, v. 2, janvier 1907).

A afirmação de La Technique sanitaire e da AGIAHM andam juntas: a centralidade dada à troca de conhecimentos nas disciplinas técnicas e uma forte presença de seus membros em serviços municipais são a base deste sucesso. A revista consegue uma cooperação entre técnicos de diferentes origens e estatutos e estabeleceu-se como referência não só para os problemas técnicos relacionados com as redes urbanas, mas também no debate sobre o desenvolvimento e expansão das cidades e da habitação popular. Em 1911, a revista tornou-se La Technique sanitaire et municipale, refletindo a transformação da associação que abria suas fileiras para o setor privado, e passou a Association générale des hygiénistes et techniciens municipaux [Associação dos higienistas e técnicos municipais AGHTM $]^{26}$. 
primeiro "encontro" entre Saturnino e Imbeaux deu-se por meio da La Technologie sanitaire no início do século, quando o engenheiro brasileiro publicou um artigo sobre o sistema de esgotos. É a partir deste momento que as suas relações irão se construir e intensificar-se, em particular no contexto da AGHTM. Em 1907, Saturnino de Brito tornou-se membro honorário: esta filiação revela o seu interesse pelas atividades da associação ${ }^{27}$, mas também o reconhecimento por parte da comunidade francófona da sua atividade profissional, que the valeu, em 1926, sob a proposta da AGHTM, a atribuição de Chevalier de La Légion d'Honneur, na qualidade de "científico e amigo da França".

ano de 1916, durante a Grande Guerra, a AGHTM organizou em Paris a importante exposição sobre a reconstrução das cidades e das regiões devastadas: é o culminar de um percurso que vai da engenharia sanitária ao urbanismo e que, em parte, será questionada no período entreguerras. Imbeaux é um dos protagonistas da exposição, membro da Comissão Organizadora e da Comissão Científica, é um dos palestrantes principais e está envolvido no ciclo das grandes conferências de "urbanismo aplicado", sob o tema da higiene urbana. Saturnino, ausente do evento, recebe um prêmio por seus livros A Planta de Santos e Notes sur le tracé sanitaire des villes, publicados, respectivamente, em 1915 e 1916. Essa exposição é um momento-chave nas carreiras de Imbeaux e Saturnino, confirmando seus papéis no cenário internacional do urbanismo e da engenharia sanitária.

As viagens: Brasil (1910), Europa (1913)

A prática social da viagem é vivenciada de forma diferente por Saturnino e Imbeaux. Para ambos os profissionais, a expertise é uma importante área de ação e uma das razões para a sua mobilidade, nacional para um e internacional para o outro. Saturnino é envolvido em uma multiplicidade de contextos, em cidades de todos os tamanhos e importância, de Norte a Sul do Brasil; Imbeaux permanece ancorado no território fronteiriço de Nancy, fornecendo conhecimentos em ambos os lados da fronteira francesa e construindo relacionamentos com colegas alemães, belgas e luxemburgueses. Dois episódios marcam as trajetórias desses dois atores, respectivamente em 1910 e 1913.

Saturnino e Imbeaux mantinham contatos desde 1906, mas se conheceram pessoalmente em 1910, quando o engenheiro francês viajou pela América do Sul, para Buenos Aires, para as exposições internacionais do centenário da República Argentina, especialmente a exposição dedicada à higiene. Esta área é de particular interesse tanto para a delegação francesa, que inclui Imbeaux, como para especialistas e empresários franceses que procuram consolidar a sua presença nos mercados latino-americanos. Outros membros da AGIAHM, como Bezault, participam neste evento. Nessa oportunidade, Imbeaux e Saturnino visitaram, juntos, as obras de Santos e Recife, nessa época em duas fases diferentes de construção. A viagem permite ao engenheiro francês apreciar as contribuições
27. Como a filiação também incluía a assinatura da revista mensal $\mathrm{da}$ Associação, La Technique sanitaire, é provável que Saturnino tivesse vários números, para não dizer a coleção completa. As citações tiradas dessa revista são muitas e constantes em toda a sua produção escrita e ele contribuiu diretamente com a revista, pois publicou alguns artigos entre $1907 \mathrm{e}$ 1924 . 
concretas de seu colega e amigo brasileiro para a engenharia sanitária, e contribuir para a reflexão sobre o abastecimento de água na capital de Pernambuco, escrevendo uma nota. Contudo, a solução proposta seria ultrapassada pela que Saturnino apresentaria no ano seguinte.

Uma segunda oportunidade de encontro ocorre no verão de 1913, durante a viagem de Saturnino para França e Grã-Bretanha. Nesta viagem, manifesta sua determinação de participar ativamente no progresso técnico da disciplina. Saturnino chegou à Europa para encontrar industriais franceses e ingleses e estudar a produção de peças que havia desenhado para as obras de saneamento de Recife. Na França, Saturnino foi de Paris para Nancy, a convite de Imbeaux, e em seguida para Lille: na época, os debates sobre as transformações urbanas eram muito acirrados nessas cidades e é possível imaginar o quanto isso interessou o engenheiro brasileiro. Esse interesse redundou na aquisição de publicações e manuais e na crescente atenção que daria ao contexto francês e aos seus atores após essa viagem. No decorrer dela, ocorreram, na Europa francófona, os primeiros eventos internacionais de urbanismo, na esteira dos de Londres e Berlim, em 1910. Do primeiro Congresso Internacional das Cidades, organizado em Gent, na Bélgica, nasceu uma importante associação: a União Internacional das Cidades. A Exposition de la "Cité moderne", primeiro evento de urbanismo na França, ocorreu em Nancy - a organização repousava numa estreita colaboração entre o meio reformador local e o pessoal do Museu Social e da Sociedade Francesa dos Arquitetos Urbanistas. Este contexto contribui para a afirmação do urbanismo, como conhecimento e know-how, e constitui a única viagem de Saturnino à Europa.

Da engenharia sanitária para o urbanismo: a construção de um diálogo

As trajetórias profissionais de Saturnino de Brito e Édouard Imbeaux permitem-nos trazer um enfoque renovado sobre o papel da engenharia sanitária na construção de conhecimentos e know-how urbanos, na França e no Brasil. No final do século XIX, em ambos os países, higiene e saneamento das cidades estão no centro das preocupações dos vereadores e reformadores: a engenharia sanitária ajuda a ampliar a discussão da habitação na cidade e fornece os conhecimentos e as ferramentas técnicas necessárias para se tomar medidas concretas.

Na França, a aprovação em 1902 da lei sobre a higiene pública obriga os municípios, em alguns casos, a conduzir pesquisas sobre as condições sanitárias e a tomar as medidas corretivas, voltadas principalmente para $\circ$ abastecimento de água e o sistema de esgotos. $\bigcirc$ mundo profissional e da reforma, a quem pertence Édouard Imbeaux, contribuiu largamente para a definição desta primeira lei que parece atribuir à engenharia sanitária um papel importante na sua implementação. A complexidade dos fenômenos urbanos, uma nova leitura da cidade histórica e o surgimento de novas disciplinas no debate sobre a cidade põe em causa gradualmente a primazia reivindicada pelos higienistas, engenheiros ou médicos. Duas vias se dispõem para estes "cientistas da cidade": abrir-se a um 
confronto mais amplo com outras disciplinas, incluindo a arquitetura, para construir um conhecimento não só para cuidar da cidade existente, mas também para propor novas formas para a cidade do futuro; e mover-se, gradualmente, mais exclusivamente para redes urbanas técnicas. A trajetória profissional de Imbeaux representa esta última via e os limites de uma abordagem puramente científica. A engenharia sanitária desaparece gradativamente, na França, na batalha para os planos das cidades, onde novos profissionais, os urbanistas, mobilizam-se nos anos 1910 e reivindicam um papel de liderança.

No Brasil, a biografia de Saturnino de Brito e suas principais realizações permitem-nos esclarecer a progressiva constituição de um saber e de um know-how sobre a transformação das cidades, construídos a partir dos princípios do saneamento urbano e da higiene pública. A engenharia sanitária constituía a principal matriz do urbanismo no Brasil, até o final dos anos 1920. Durante muito tempo, a cidade foi apreendida a partir das redes técnicas subterrâneas, como os esgotos ou os sistemas de adução e escoamento de águas. Saturnino apropriou-se dessa abordagem técnica e introduziu o estudo topográfico como elemento-chave para a construção de redes técnicas e viárias eficientes. A forma do tecido urbano não era mais definida a priori, mas segundo o contexto físico. Assim, Saturnino ampliou a área de aplicação da engenharia sanitária, que passou do saneamento à expansão urbana.

Em um contexto brasileiro marcado por rápido desenvolvimento da infraestrutura urbana, a salubridade torna-se a palavra de ordem para a expansão das cidades através da criação de novos bairros. Saturnino de Brito, em seguida, desenvolveu ferramentas da engenharia sanitária para fazer interagir com outras dimensões necessárias à construção da cidade: social, arquitetônica e cívica. A abordagem técnica é ultrapassada e torna-se o elemento de partida da disciplina urbanística emergente.

A experiência profissional de Saturnino de Brito mostra ser possível conciliar as exigências da salubridade de uma cidade com um traçado urbano estético ${ }^{28}$. As soluções propostas pela engenharia sanitária para as questões utilitárias e sociais não se opõem à busca artística dos urbanistas e arquitetos que atuam nos melhoramentos e na expansão das cidades. $\bigcirc$ debate europeu da época era mobilizado em torno da oposição entre estética das cidades e ciência das cidades. Saturnino parece ter encontrado uma solução de compromisso interessante. A especificidade das cidades brasileiras e do seu clima permitiu-lhe fazer propostas que levassem em conta os princípios estéticos no traçado urbano sem deixar de respeitar os preceitos da higiene. Saturnino aplicou esse princípio com muito rigor e, com as suas realizações e os seus escritos, contribuiu para a afirmação, no Brasil, de uma abordagem global, técnica e estética, da transformação das cidades.
28. Ver Angelo Bertoni (2014). 


\section{REFERÊNCIAS}

\section{FONTES TEXTUAIS PRIMÁRIAS IMPRESSAS}

ASSOCIATION générale des ingénieurs, architectes et hygiénistes municipaux. La Technique sanitaire: Berger-Levrault, Paris, 1906-1911.

ASSOCIATION générale des hygienistes et techniciens municipaux, La Technique sanitaire et municipale: Berger-Levrault, Paris, 1911-1929.

BARDE, Charles. Salubrité des habitations et hygiène des villes: L. Stapelmohr, Genebra, 1891.

BRITO, Francisco Rodrigues Saturnino de. Notes sur le tracé sanitaire des villes: Imprimerie Chaix, Paris, 1916.

BRITO, Francisco Rodrigues Saturnino de. Obras Completas. Rio de Janeiro: Imprensa Nacional, 1943-1944. (v. I-XXIII).

FREIRE, Victor da Silva. A cidade salubre. São Paulo: Typografia Brazil de Rothschild, 1915.

HÖPFNER, Karl; IMBEAUX, Édouard. Assainissement de Luxembourg et de sa Banlieue. Bulletin mensuel de l'Association des ingénieurs luxembourgeois, v. 6, n. 1, p. 4-10, juin 1906.

IMBEAUX, Édouard. L'alimentation en eau et l'assainissement des villes: compte rendu des derniers progrès et de l'état actuel de la science sur ces questions. Paris: E. Bernard et Cie, 1902.

IMBEAUX, Édouard; MACÉ, Eugène. Hygiène générale des villes. Paris: J.-B. Baillière et fils, 1910.

LA TECHNOLOGIE SANITAIRE. Lovaina: Imprimerie des Trois Rois, 1895-1905.

PUTZEYS, Émile; SCHOOFS, Frans (Ed.). Traité de technique sanitaire. Paris: Ch. Béranger, 1925.

ROCHARD, Jules (Ed.). Encyclopédie d'hygiène et de médecine publique. Paris: Lecrosnier et Babé, 1890-1897. (tomo III, Hygiène urbaine, 1891; tomo IV, Hygiène urbaine, libro III; Hygiène rurale, libro IV, 1892).

SOUZA, Robert de. L'avenir de nos villes. Nice capitale d'hiver. Paris: Berger-Levrault, 1913.

\section{LIVROS, ARTIGOS E DISSERTAÇÕES}

ANDRADE, Carlos Roberto Monteiro de. A peste e o plano. O urbanismo sanitarista do engenheiro Saturnino de Brito. 1992. 282 f. Dissertação (Mestrado) - Faculdade de Arquitetura e Urbanismo, Universidade de São Paulo, São Paulo, 1992.

ANDRADE, Carlos Roberto Monteiro de. De Viena a Santos: Camillo Sitte e Saturnino de Brito. In: SITTE, Camillo. A construção das cidades segundo seus princípios artísticos. São Paulo: Editora Ática, 1996a, p. 206-234. 
ANDRADE, Carlos Roberto Monteiro de. Le pittoresque et le sanitaire. Sitte, Martin, Brito, traductions et métamorphoses de savoirs professionnels, 1889-1929. Genèses, Paris, n. 22, p. 64-86, mars 1996b.

BARLES, Sabine. La ville délétère: médecins et ingénieurs dans l'espace urbain, XVIIIe-XIXe siècles. Seyssel: Champ Vallon, 1999.

BERTONI, Angelo. Les architectes et la naissance de l'urbanisme de plan: pratiques locales, réseaux nationaux et transnationaux en France et en Europe francophone, 1880-1920). 2006, 518 f. Tese (Doutorado) - École des hautes etudes en sciences sociales, Paris, 2006.

BERTONI, Angelo. Saturnino de Brito e a construção da ciência do urbanismo no Brasil: entre importações, adaptações e inovações. In: BERTONI, Angelo; SALGADO, Ivone (Ed.). Da construção do território ao planejamento das cidades: competências técnicas e saberes profissionais na Europa e nas Américas, 1850-1930. São Carlos: Rima, 2010, p. 137-147.

BERTONI Angelo. L'ingénierie sanitaire et la construction d'un nouveau paysage urbain au Brésil: l'œuvre de Saturnino de Brito, 1898-1909. In: $135^{\circ}$ Congrès National des Sociétés Historiques et Scientifiques. Ordonner les lieux et les hommes. Paris: Éditions du CTHS, 2014, p. 106-118.

BEVERIDGE, Charles; ROCHELEAU, Paul. Frederick Law Olmsted: Designing the American landscape. Nova York: Universe Publishing, 1998.

BOURDELAIS Patrice (Ed.). Les Hygiénistes: enjeux, modèles et pratiques (XVIIIe-XXe siècles). Paris: Belin, 2001.

CARVAlHO, Maria Cristina Wolff de. Ramos de Azevedo. São Paulo: EDUSP, 2000.

CLAUDE, Viviane. L'Association générale des hygiénistes et techniciens municipaux (AGHTM): école et/ou lobby, 1905-1930. Paris: PUCA, 1987

CLAUDE, Viviane. Technique sanitaire et réforme urbaine : l'Association générale des hygiénistes et des techniciens municipaux, 1905-1920. In: TOPALOV Christian (Ed.). Laboratoires du nouveau siècle. Paris: Éditions EHESS, 1999, p. 269-298.

JULLIARD, Jacques. Le monde des revues au début du siècle, introduction. Cabiers Georges Sorel, Paris, n. 5, p. 3-9, 1987.

LECLERC, Bénédicte (Ed.). Claude Nicolas Forestier 1861-1930: Du jardin au paysage urbain. Paris: Picard, 1994.

LEME, Maria Cristina da Silva. A formação do pensamento urbanístico no Brasil, 1895-1965. In: _. Urbanismo no Brasil 1895-1965. São Paulo: Studio Nobel, 1999, p.20-38.

MELOSI, Martin. The Sanitary City: Urban Infrastructure in America from Colonial Times to the Present. Baltimore: The Johns Hopkins University Press, 2000.

MONTIGNY, Gilles. De la ville à l'urbanisation: essai sur la genèse des études urbaines françaises en géographie, sociologie et statistique sociale. Paris: L'Harmattan, 1992.

Annals of Museu Paulista. v. 23. n.1. Jan.-Jun. 2015. 
MURARD Lion, ZYLBERMAN Patrick. Entre conservatisme et réforme: l'alliance d'hygiène sociale. In: CHAMBELLAND Colette (Ed.). Le Musée social en son temps. Paris: Presses ENS, 1998, p. 229-267.

PICON, Antoine. Architectes et ingénieurs au siècle des Lumières. Marselha: Éditions Parenthèses, 1988.

PLUET-DESPATIN Jacqueline; LEYMARIE Michel; MOLLIER Jean-Yves (Ed.). La Belle époque des revues: 1880-1914. Paris: Éditions de l'I.M.E.C., 2002.

TELLES, Pedro Carlos da Silva. Historia da engenharia no Brasil. Rio de Janeiro: Livros Técnicos e Científicos, 1984.

ZUCCONI, Guido. La città contesa. Dagli ingegneri sanitari agli urbanisti, 1855-1942. Milão: Jaca Book, 1989.

Artigo apresentado em 28/10/2014. Aprovado em 29/04/2015. 